\title{
Can insulin administration cause an acute metabolic acidosis in vivo?
}

\section{An experimental study in dogs}

\author{
J.M.Goguen, M. L.Halperin \\ Division of Nephrology, St Michael's Hospital, University of Toronto, Toronto, Canada
}

\begin{abstract}
Summary. Insulin is the cornerstone of therapy for diabetic ketoacidosis because it causes the rate of ketoacid production to fall; this action takes several hours to occur. Insulin also causes $\mathrm{H}^{+}$to be transported from the intracellular fluid to the extracellular fluid in vitro. The purpose of this study was to determine if insulin led to the acute export of $\mathrm{H}^{+}$from the intracellular fluid in vivo. If so, we wished to determine if this also occurred during chronic metabolic acidosis, to quantitate the magnitude of the $\mathrm{H}^{+}$shift, and to evaluate the mechanisms involved. The administration of low- or highdose insulin to normal dogs and high-dose insulin to dogs with chronic metabolic acidosis caused the concentration of bicarbonate in plasma to decline by close to $3 \mathrm{mmol} / 1$. The
\end{abstract}

$\mathrm{PCO}_{2}$ fell by close to $15 \%$ in all three groups of dogs, so one component of the fall was due to hyperventilation. As the $\mathrm{pH}$ of blood did not change, a primary metabolic acidosis also occurred. The fall in bicarbonataemia was not due to net accumulation of organic acids or to a loss of bicarbonate or organic anions in the urine. Taken together, insulin, when given at doses used to treat diabetic ketoacidosis, might induce a significantly greater degree of acidaemia in the extracellular fluid acutely after it is given.

Key words: Endogenous acid production, intracellular $\mathrm{pH}$, insulin, metabolic acidosis, $\mathrm{Na}^{+} / \mathrm{H}^{+}$antiporter, $\mathrm{PCO}_{2}$
The most common association between insulin and metabolic acidosis is the development of ketoacidosis in which ketoacids are produced due to the combination of high levels of glucagon and a relative lack of insulin [1]. This ketoacidosis can become severe in the patient with Type 1 (insulin-dependent) diabetes mellitus, but is usually mild in degree in chronic fasting [2]. Insulin may influence the degree of acidosis in another way in that it leads to alkalinization of cells in vitro [3-5]. Thus, administration of insulin might cause acidaemia in the extracellular fluid (ECF) together with a rise in intracellular $\mathrm{pH}$. If $\mathrm{H}^{*}$ were transported into the ECF when insulin was administered early in the treatment of a patient with a severe degree of diabetic ketoacidosis (DKA), an acute exacerbation of acidemia might occur. This is particularly critical since during severe metabolic acidosis, most protons are buffered in the intracellular fluid (ICF) [6].

The purpose of this investigation was to determine if extracellular acidosis occurred in vivo shortly after insulin was administered and if so, to quantitate the extent to which it occurred and provide some insights into its basis. We also addressed the dose of insulin required and if the phenomenon was independent of the initial acid-base balance. Three series of experiments were employed: first, a normal acid-base series given a high dose of insulin (a dose similar to that used in vitro [5]), second, a normal acidbase series given a lower dose of insulin (one that is used to treat DKA) and third, a series with chronic metabolic acidosis given the high dose of insulin. Results to be reported indicate that more severe acidosis developed in the $\mathrm{ECF}$ in all three series of experiments. The underlying mechanism for the ECF acidosis was also examined by quantitating endogenous net acid production, the shift of cations across the ECF: ICF interface, the loss of bicarbonate and changes in the $\mathrm{PCO}_{2}$.

\section{Materials and methods}

Chemicals: Enzymes, cofactors and metabolic intermediates were obtained from Sigma Chemical Company (St. Louis, Mo., USA). All other reagents were of the highest purity available.

Animals: Mongrel dogs of either sex $(19 \pm 1 \mathrm{~kg})$ were prepared in two ways: dogs with normal acid-base balance were fed their usual diet, and dogs with chronic metabolic acidosis received $5 \mathrm{mmol}$ $\mathrm{NH}_{4} \mathrm{Cl} / \mathrm{kg}$ body weight twice a day with meals for 5 days. Food was withheld on the morning of study.

Experimental procedure: Dogs were anaesthetized with phenobarbital $(25 \mathrm{mg} / \mathrm{kg}$ i. $v$. with additional doses as needed to maintain a con- 
Table 1. Dogs treated with insulin

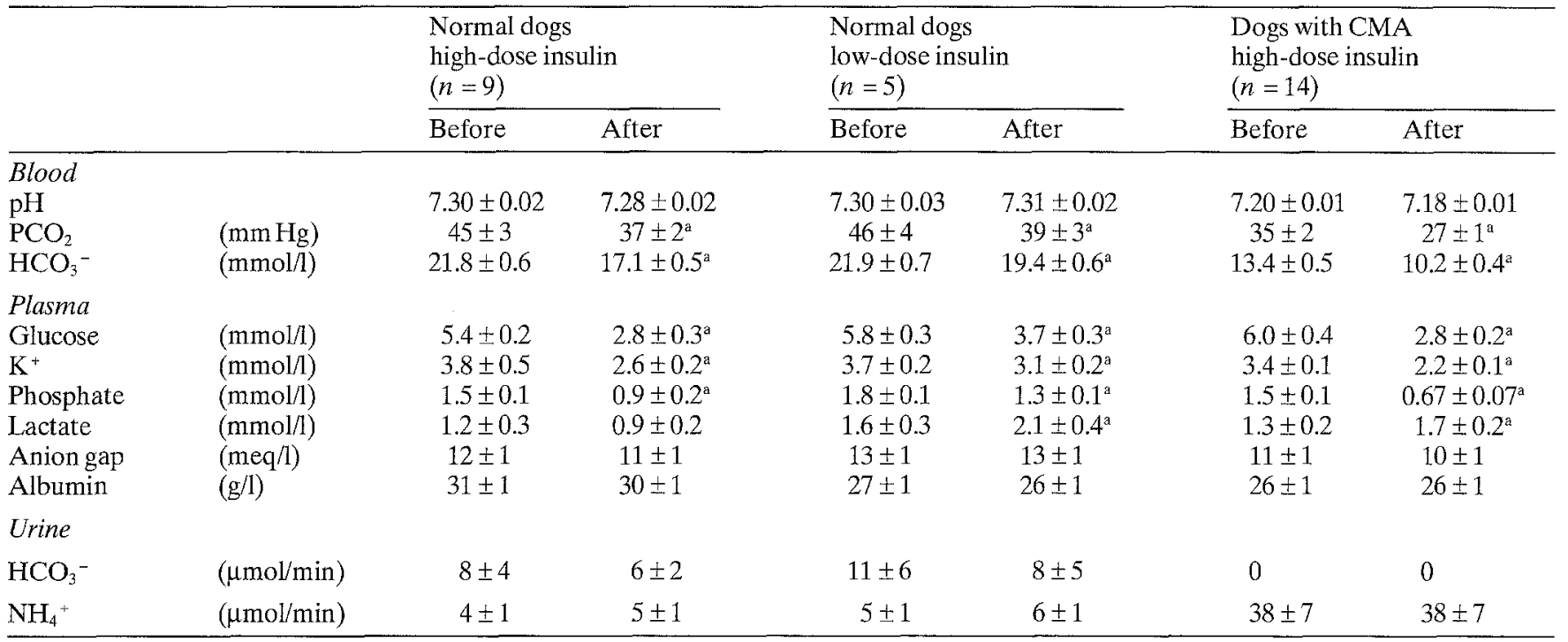

${ }^{a} p<0.05$ for paired values.

For details, see Methods. Results from the 60-min control period and the 40 to 60 -min period after insulin administration (mean $\pm S E M$ ) are shown. Urine was collected for the entire $60 \mathrm{~min}$ of the insulin

stant depth of anaesthesia throughout the experiment). The dogs were permitted to breathe spontaneously throughout the experiment. The abdomen was opened by midline incision and catheters were inserted into both ureters, the internal jugular veins for infusions and in the femoral artery for blood sampling. To maintain a normal ECF volume and urine output after surgery, each dog received a continuous i.v. infusion containing $140 \mathrm{mmol} / \mathrm{l} \mathrm{NaCl}$, $10 \mathrm{mmol} / \mathrm{K} \mathrm{KCl}$ and $82 \mathrm{mmol} / \mathrm{l}$ mannitol at a rate of $6.7 \mathrm{ml} / \mathrm{min}$ for $60 \mathrm{~min}$ after the surgery; at this point the infusion rate was reduced so that the total input $(1.4 \mathrm{ml} / \mathrm{min})$ matched the rate of urine output. Urine was collected for 15 -min periods and an arterial blood sample was obtained at the beginning and end of each period. The values in plasma in this 60-min control period did not vary appreciably and represent the 'before insulin' value.

At the end of the control period, five normal dogs received a bolus of $0.1 \mathrm{IU} / \mathrm{kg}$ regular beef and pork insulin and this was followed by a constant infusion of $0.1 \mathrm{IU} \cdot \mathrm{kg}^{-1} \cdot \mathrm{h}^{-1}$. Nine normal dogs and 14 dogs with metabolic acidosis received the high-dose insulin protocol - a bolus of $1.5 \mathrm{IU} / \mathrm{kg}$ body weight followed by a constant infusion of $1.8 \mathrm{IU}$ insulin $\cdot \mathrm{kg}^{-1} \cdot \mathrm{h}^{-1}$. Samples of blood were obtained at 20,40 and $60 \mathrm{~min}$ and urine was collected as described above for the three 20-min collections after the bolus of insulin was administered; a steady state was achieved by $40 \mathrm{~min}$. Six additional normal dogs and five additional dogs with metabolic acidosis did not receive insulin and had the control period extended for an additional $1 \mathrm{~h}$ to serve as time controls.

Analytical methods: The $\mathrm{pH}, \mathrm{PCO}_{2}$ and $\mathrm{PO}_{2}$ of blood and the $\mathrm{pH}$ of urine were measured anaerobically at $37^{\circ} \mathrm{C}$ with a digital acid-base analyser (Corning 178 blood $\mathrm{pH}$ analyzer, Medfield, Mass., USA). Analytical methods for haemoglobin, metabolites, oxygen, sodium, potassium and creatinine were as previously described [7]. The concentration of bicarbonate in plasma was calculated using a $\mathrm{pK}^{\prime}$ of 6.10 and a solubility factor for $\mathrm{CO}_{2}$ of $0.0301[8,9]$. Insulin was measured by radioimmunoassay.

\section{Statistical analysis}

Results are reported as the mean \pm SEM. For each dog, the values at the end of the control period were compared to values (at 40 and $60 \mathrm{~min}$ ) in the insulin period; since the latter two values were vir- period. Urinary net charge is a marker of urinary anion excretion and is defined as the urinary $\left(\mathrm{Na}^{+}+\mathrm{K}^{+}-\mathrm{Cl}^{-}\right) \times$flow. CMA, chronic metabolic acidosis

tually identical, they were treated as single values for ease of reporting. Statistical comparisons were performed by paired analyses on data from individual dogs using the two-tailed Student's $t$-test.

\section{Results}

All the dogs had the expected fall in the concentrations of plasma glucose, $\mathrm{K}^{+}$and phosphate within 40 min after insulin was administered (Table 1 ). In each series of experiments, there was also a significant fall in the concentration of bicarbonate in plasma; this fall was $4.7 \pm 0.6 \mathrm{mmol} / 1$ in the normal dogs given a high dose of insulin and $2.5 \pm 0.7 \mathrm{mmol} / 1$ in the normal dogs given the lower dose of insulin (Table 1). In the acidotic dogs, the fall in plasma bicarbonate was $3.2 \pm 0.5 \mathrm{mmol} / \mathrm{l}$, thus there was a larger proportionate fall in the concentration of bicarbonate in plasma in these dogs. In six additional normal dogs and five dogs with chronic metabolic acidosis that did not receive insulin, there were no significant changes in plasma $\mathrm{pH}$, bicarbonate, lactate or the anion gap in a second 60min time control period (results not shown).

To provide insights into the underlying mechanism of the ECF acidosis induced by insulin, several possibilities were examined. First, there was no evidence of ongoing endogenous net acid production in any dog as the anion gap in plasma did not rise appreciably nor did the urine contain an increase in unmeasured anions following insulin administration (Table 1). Further, although there was a small rise in the concentration of L-lactate in blood, this rise was less than $1 \mathrm{mmol} / \mathrm{l}$ following the administration of insulin (Table 1). Second, there was no evidence of loss of an appreciable quantity of bicarbonate in the urine, but gastrointestinal excretions were not examined. Third, a fall in blood $\mathrm{PCO}_{2}$ can result in a reduction in the concentration of bicarbonate due to the shift of $\mathrm{H}^{+}$out of cells 
down their concentration gradient; in the data reported in Table 1, the fall in $\mathrm{PCO}_{2}$ was not associated with a rise in blood $\mathrm{pH}$. Thus, the data were most consistent with the shift of $\mathrm{H}^{+}$ions out of cells, due in part to a fall in $\mathrm{PCO}_{2}$ and not due to endogenous net acid production.

Any shift of $\mathrm{H}^{+}$ions out of cells must be accompanied by a shift of the equivalent amount of cation into cells or of an anion out of cells to maintain electroneutrality. The fall in the concentration of $\mathrm{K}^{+}$in plasma was much less than the fall in bicarbonate. Also, there was a net shift of phosphate into cells (Table 1). Thus, if there was an exit of $\mathrm{H}^{+}$ from cells, it was probably accompanied by the entry of $\mathrm{Na}^{+}$to maintain electroneutrality.

\section{Discussion}

The purpose of this study was to determine if acute administration of insulin would cause a shift of $\mathrm{H}^{+}$into the ECF as suggested by in vitro experiments $[3,4,5,10]$. In all three dog models, the actions of insulin were evident because there was a fall in the concentrations of glucose, $\mathrm{K}^{+}$ and phosphate in plasma. A major new observation was the significant fall in bicarbonate concentration in plasma shortly after insulin acted.

During the net production of acids, a neutral compound such as glucose is converted to an anion such as lactate (plus a $\mathrm{H}^{+}$) [11]. This anion must be retained in the body or excreted without $\mathrm{H}^{+}$or $\mathrm{NH}_{4}{ }^{+}$to produce a net gain of $\mathrm{H}^{+}$in the body [12]. Therefore, the hallmark of net endogenous acid production is the accumulation of new anions in the body or urine [13]. In all three models, the anion gap in plasma $\left(\mathrm{Na}^{+}+\mathrm{K}^{+}-\mathrm{Cl}^{-}-\mathrm{HCO}_{3}{ }^{-}\right)$did not rise during the insulin period, nor was there a net excretion of anions without $\mathrm{H}^{+}$or $\mathrm{NH}_{4}{ }^{+}$ions. Also, the concentration of L-lactate in blood rose by only a fraction of a $\mathrm{mmol} / \mathrm{l}$. Thus, it is unlikely that endogenous net acid production accounted for the fall in bicarbonate concentration.

The content of bicarbonate in the ECF could fall if sodium bicarbonate was lost from the body either in the urine or gastrointestinal secretions. In all three models, there was no significant loss of bicarbonate in the urine. The volume and concentration of bicarbonate was not measured in the gastrointestinal secretions, so this must remain a possible explanation. Nevertheless, there are no data reported to suggest that insulin causes metabolic acidosis due to a temporary loss of bicarbonate via the gastrointestinal tract. If anything, insulin may augment the secretion of $\mathrm{HCl}$ in the stomach and raise the concentration of bicarbonate in the ECF [14].

If bicarbonate disappeared due to conversion to carbon dioxide and water, the source of $\mathrm{H}^{+}$was probably the ICF as there are too few $\mathrm{H}^{+}$(free or buffered) in the ECF to consume a large quantity of bicarbonate. The shift of $\mathrm{H}^{+}$could occur either due to a fall in the $\mathrm{PCO}_{2}$, or due to a more direct effect of insulin. Considering a fall in $\mathrm{PCO}_{2}$ first, an acute fall should lead to a rise in blood $\mathrm{pH}$ if this were the sole cause for the observed fall in the concentration of bicarbonate - there was no rise in $\mathrm{pH}$ of plasma during the insulin period. Hence there must be an addi- tional mechanism to explain this fall in bicarbonate. In quantitative terms, the expected fall in bicarbonate when dogs were hyperventilated is close to $2.5 \mathrm{mmol} / \mathrm{l}$ for each halving of the $\mathrm{PaCO}_{2}[15]$.

The final possible explanation for the fall in bicarbonate concentration in plasma to consider is that insulin led to a shift of $\mathrm{H}^{+}$out of cells independent of respiratory alkalosis. This movement can only occur if a cation enters the ICF in exchange for $\mathrm{H}^{+}$, or if an anion leaves the ICF. Since there were no new anions found in the ECF, a cation $\left(\mathrm{Na}^{+}\right.$and/or $\left.\mathrm{K}^{+}\right)$should have entered the ICF to maintain electroneutrality. Since the decline in bicarbonate concentration exceeded the fall in $\mathrm{K}^{+}$in plasma, by process of elimination, the most likely cation present in sufficient quantity in the ECF for this shift with $\mathrm{H}^{+}$is $\mathrm{Na}^{+}$. Unfortunately, balance studies are not accurate enough to detect a $16 \mathrm{mmol}$ loss of $\mathrm{Na}^{+}(4 \mathrm{mmol} / \mathrm{l} \times$ the $\mathrm{EFC}$ volume of $4 \mathrm{li}-$ tres) in a total pool of $\mathrm{Na}^{+}$in the ECF of close to $600 \mathrm{mmol}$.

There are data obtained in vitro to support the hypothesis that insulin induces a rise in intracellular $\mathrm{pH}$ due to the export of $\mathrm{H}^{+}$- examples include myocytes [3,5], renal proximal cells [16] and in some studies in adipocytes [17, 18]. When insulin was added to muscle cells in vitro, there was a rapid, significant and sustained rise in intracellular $\mathrm{pH}$ which could be abolished by replacing $\mathrm{Na}^{+}$in the medium with another cation or by adding amiloride in a quantity sufficient to block the $\mathrm{Na}^{+} / \mathrm{H}^{+}$antiporter $[4,5]$. The lower the initial ICF $\mathrm{pH}$, the greater was the rise in ICF $\mathrm{pH}$ induced by insulin [19].

To determine if the effect of insulin on ICF and ECF $\mathrm{pH}$ could occur in a physiological setting, the concentration of insulin required to elicit this change needs to be examined. In experiments with myocytes, the effect on intracellular $\mathrm{pH}$ required very high concentrations of insulin ranging from $2 \times 10^{-8} \mathrm{mmol} / 1$ to $1 \times 10^{-6} \mathrm{mmol} / \mathrm{l}$ (ICF $\mathrm{pH}$ changed from 0.03 to 0.14 units, respectively). Dogs receiving high-dose insulin had measured circulating insulin levels close to $2 \times 10^{-7} \mathrm{mmol} / \mathrm{l}$.

It might be important from a clinical perspective to consider the impact of a shift of $\mathrm{H}^{+}$following the administration of insulin. Insulin is administered to suppress the production of ketoacids during therapy for DKA, an action that requires several hours. If the $\mathrm{Na}^{+} / \mathrm{H}^{+}$antiporter was activated acutely, the result would be both a higher amount of $\mathrm{H}^{+}$in the ECF and a higher amount of $\mathrm{Na}^{+}$in the ICF, both of which could conceivably be detrimental; possibly, the rise in intracellular $\mathrm{pH}$ might be beneficial. A second instance where activation of the $\mathrm{Na} / \mathrm{H}^{+}$ion antiporter could be important focuses on a rise in intracellular $\mathrm{Na}^{+}$concentration. For example, $\mathrm{Na}^{+}$is an effective osmole, unlike the $\mathrm{H}^{+}$it replaces (the latter did not contribute to osmolality when it was bound to proteins); thus water should enter cells and result in cell swelling. This possibility has been raised as an explanation for the cerebral oedema that can occur following treatment with insulin [20]. There are other possible ways that a rise in intracellular $\mathrm{Na}^{+}$can influence body function. In the patient with essential hypertension, hyperinsulinaemia could exacerbate the degree of hypertension if it stimulates the $\mathrm{Na}^{+} / \mathrm{H}^{+}$pump in smooth muscle cells. 
An increased $\left[\mathrm{Na}^{+}\right]$in their ICF could lead to an increase in intracellular $\left[\mathrm{Ca}^{2+}\right]$ and thus to smooth muscle contraction and increased peripheral resistance. Finally, the metabolic alkalosis which follows glucose feeding to obese, chronically fasted subjects may be another possible manifestation of stimulation of the $\mathrm{Na}^{+} / \mathrm{H}^{+}$antiporter by insulin [21]. Should insulin stimulate the $\mathrm{Na}^{+} / \mathrm{H}^{+}$antiporter in the luminal membrane of cells of the proximal convoluted tubule, this would result in $\mathrm{Na}^{+}$ reabsorption and $\mathrm{H}^{+}$secretion. As a result, the increased maximal reabsorptive capacity for bicarbonate and the higher renal bicarbonate threshold that occurred when these patients were refed could both be explained by this mechanism.

In summary, in three different settings, an ECF acidosis resulted following the administration of insulin in vivo. This effect was dose dependent and occurred in both normal dogs and those with chronic metabolic acidosis. Our data are most consistent with this effect being due to a fall in $\mathrm{PCO}_{2}$ and the export of $\mathrm{H}^{+}$from cells. Numerous in vitro models show that insulin can stimulate the $\mathrm{Na}^{+} / \mathrm{H}^{+}$ antiporter and result in intracellular alkalosis. Further studies are required to determine if this effect also occurs in patients with DKA after treatment with insulin.

Acknowledgements. The authors are very grateful to Dr. S. Cheema Dhadli and K.S. Kamel for helpful discussions and critique during the preparation of the manuscript. We are also indebted to Mr. C. Bun-Chen, Ms. S. Tang and Ms. E. Singer for their technical assistance and to Ms. J. Mangat for secretarial assistance.

\section{References}

1. McGarry JD, Woeltje KF, Kuwajima M, Foster DW (1989) Regulation of ketogenesis and the renaissance of carnitine palmitoyltransferase. Diab Metab Rev 5: 271-284

2. Owen O, Caprio S, Reichard GJ, Mozzoli M, Boden G, Owen R (1983) Ketosis of starvation: a revisit and new perspectives. Clin Endocrinol Metab 12: 359-379

3. Moore RD (1979) Elevation of intracellular $\mathrm{pH}$ by insulin in frog skeletal muscle. Biochem Biophys Res Commun 91: 900-904.

4. Moore RD (1981) Stimulation of $\mathrm{Na}: \mathrm{H}$ exchange by insulin. Biophys J 33: 203-210

5. Klip A, Ramlal T, Cragoe EJ Jr (1986) Insulin-induced cytoplasmic alkalinization and glucose transport in muscle cells. Am $\mathbf{J}$ Physiol 250: C720-C728

6. Swan RC, Pitts RF (1955) Neutralization of infused acid by nephrectomized dogs. J Clin Invest 34: 205-212

7. Halperin ML, Vinay P, Gougoux A, Pichette C, Jungas RL (1985) Regulation of the maximum rate of renal ammoniagenesis in the acidotic dog. Am J Physiol 248: F607-F615
8. Hastings AB, Sendroy $J \mathrm{Jr}(1925)$ The effect of variation in ionic strength on the apparent first and second dissociation constants of carbonic acid. J Biol Chem 65: 445-455

9. Van Slyke DD, Sendroy J, Hastings AB, Neill JM (1928) Studies of gas and electrolyte equilibria in blood. X. The solubility of carbon dioxide at $38^{\circ} \mathrm{C}$ in water, salt solution, serum and blood cells. J Biol Chem 78: 765-799

10. Moore RD, Gupta RK (1980) Effect of insulin on intracellular $\mathrm{pH}$ as observed by ${ }^{31} \mathrm{P}$ NMR spectroscopy. J Quantum Chem 7 : $83-92$

11. Halperin ML, Kamel KS, Cheema-Dhadli S (1992) Lactic acidosis, ketoacidosis, and energy turnover: "Figure" you made the correct diagnosis only when you have "counted" on it - Quantitative analysis based on principles of metabolism. Mt Sinai J Med 59: 1--12

12. Halperin ML, Jungas RL (1983) Metabolic production and renal disposal of hydrogen ions. Kidney Int 24: 709-713

13. Halperin ML, Vasuvattakul S, Bayoumi A (1991) A modified classification of metabolic acidosis: a pathophysiologic approach. Nephron 60: 129-133

14. Gillespie G, Elder J, Smith I, Kennedy F, Gillespie I, Kay A, Campbell E (1972) Analysis of basal acid secretion and its relation to insulin response in normal and duodenal ulcer subjects. Gastroenterology 62: 903-911

15. Bercovici M, Chen C, Goldstein M, Stinebaugh B, Halperin M (1983) Effect of acute changes in the $\mathrm{PaCO} 2$ on acid-base parameters in normal dogs and dogs with metabolic acidosis or alkalosis. Can J Physiol Pharmacol 61: 166-173

16. Fine LG, Badie-Dezfooly B, Lowe AG, Hamzeh A, Wells J, Sa lehmoghaddam $\mathrm{S}$ (1985) Stimulation of $\mathrm{Na}^{+} / \mathrm{H}^{-}$antiport is an early event in hypertrophy of renal proximal tubular cells. Proc Natl Acad Sci USA 82: 1736-1740

17. Mukherjee SP, Mukherjee C (1981) Metabolic activation of adipocytes by insulin accompanied by an early increase in intracellular pH. Ann NY Acad Sci 372: 347-351

18. Stark R, Read P, O'Doherty J (1980) Insulin does not act by causing a change in membrane potential or intracellular free sodium potassium concentration of adipocytes. Diabetes 29:1040-1043

19. Moore RD, Fidelman ML, Seeholzer SH (1979) Correlation between insulin action upon glycolysis and change in intracellular pH. Biochem Biophys Res Commun 91: 905-910

20. Van der Meulen JA, Klip A, Grinstein S (1987) Possible mechanism for cerebral oedema in diabetic ketoacidosis. Lancet $\mathrm{I}$ : 306-308

21. Stinebaugh BJ, Schloeder FX (1972) Glucose induced alkalosis in fasting subjects: relationship to renal bicarbonate reabsorption during fasting and refeeding. J Clin Invest 51: 1326-1336

Received: 1 March 1993

and in revised form: 11 May 1993

Professor M. L. Halperin

St. Michael's Hospital Annex

Research Wing, Lab 1

38 Shuter Street

Toronto, Ontario

Canada, M5B 1 A6 